\title{
Resistência genética em genótipos de feijoeiro a Curtobacterium flaccumfaciens pv. flaccumfaciens
}

\author{
Valmir Luiz de Souza ${ }^{1,3}$, Antonio Carlos Maringoni ${ }^{1,4}$, Sérgio Augusto Morais Carbonel12, Margarida Fumiko Ito ${ }^{2}$
}

${ }^{1}$ Faculdade de Ciências Agronômicas, UNESP, Departamento de Produção Vegetal, Setor de Defesa Fitossanitária, CP 237, CEP 18.603-970, Botucatu, SP., e-mail: vlsouza@aptaregional.sp.gov.br, maringoni@fca.unesp.br.; ${ }^{2}$ Instituto Agronômico (IAC), CP 28, CEP 13001-970, Campinas, SP. ${ }^{3}$ Bolsista da CAPES; ${ }^{4}$ Bolsista do CNPq. Parte da Tese de Doutorado do primeiro autor.

Autor para correspondência: Valmir Luiz de Souza.

Data de chegada: 04/11/2004. Aceito para publicação em: 08/08/2005.

\begin{abstract}
Souza, V.L.; Maringoni, A.C.; Carbonell, S.A.M.; Ito, M.F. Genetic resistance to Curtobacterium flaccumfaciens pv. flaccumfaciens in bean genotypes. Summa Phytopathologica, v.32, n.4, p.339-344, 2006.

Curtobacterium flaccumfaciens pv. flaccumfaciens (Cff), the causal agent of the bacterial wilt of common bean (Phaseolus vulgaris), is a vascular pathogen of difficult control. The disease was first detected in Brazil 1995, in São Paulo State. Due to the difficulty in controlling this disease, genetic resistance has been the better option. The aim of this study was to evaluate the reaction of common bean genotypes to the bacterial wilt, in 333 accesses of the bean plant germplasm database of the Instituto Agronômico de Campinas (IAC). Highly resistant and susceptible bean genotypes were selected for the observation of Cff colonization in the xylem vessel by scanning electron microscopy. The results of the screening for genetic resistance in 333 genotypes indicated variability in relation to a Cff Feij 2634

isolate. The materials were classified into 4 resistance level groups: 29 highly resistant genotypes (8.7\%), 13 resistant genotypes $(3.9 \%)$, 18 moderately resistant genotypes $(5 \%)$ and 273 susceptible genotypes $(81 \%)$. From these results, about $18 \%$ of the genotypes ranging from highly to moderately resistant - may be useful for the genetic breeding program as a source of resistance genes for Cff. Using scanning electron microscopy, xylem vessels of highly resistant genotypes presented a number of bacterial agglutinations involved by filaments and tangled structures under punctuations of the xylem vessel wall not observed in susceptible genotypes, suggests the activation of structural and biochemical defense mechanisms in resistant plants.
\end{abstract}

Additional keywords: Phaseolus vulgaris, germplasm, bacterial wilt of bean.

\section{RESUMO}

Souza, V.L.; Maringoni, A.C.; Carbonell, S.A.M.; Ito, M.F. Resistência genética em genótipos de feijoeiro a Curtobacterim flaccumfaciens pv. flaccumfaciens. Summa Phytopathologica, v.32, n.4, p.339-344, 2006.

Curtobacterium flaccumfaciens pv. flaccumfaciens (Cff) agente causal da murcha-de-curtobacterium em feijoeiro (Phaseolus vulgaris), é um patógeno vascular de difícil controle. A doença foi detectada pela primeira vez no Brasil na safra das águas de 1995, no Estado de São Paulo. Por se tratar de uma doença de difícil controle, a resistência genética tem sido a melhor opção. O objetivo deste trabalho foi avaliar a reação de genótipos de feijoeiro à murcha-de-curtobacterium, frente a 333 acessos pertencentes ao banco de germoplasma de feijoeiro do Instituto Agronômico de Campinas (IAC). Oportunamente, foram selecionados genótipos de feijoeiro altamente resistentes e suscetíveis, com a finalidade de comparar a colonização de Cff no vaso do xilema a partir da visualização sob microscopia eletrônica de varredura. Os resultados da triagem da resistência genética em genótipos de feijoeiro indicaram a existência de variabilidade genética nas amostras dos 333 genótipos avaliados, ao isolado de Cff Feij 2634. Os materiais foram classificados em 4 grupos de resistência: 29 genótipos $(8,7 \%)$ comportaram-se como altamente resistentes, 13 genótipos $(3,9 \%)$ como resistentes, 18 genótipos (5\%) como moderadamente resistentes e 273 genótipos (81\%) suscetíveis. A partir dos resultados obtidos, cerca de $18 \%$ dos genótipos de feijoeiros, desde altamente resistentes à moderadamente resistentes, poderão ser úteis para o programa de melhoramento genético como fonte de genes para resistência a Cff. Através da microscopia eletrônica de varredura, foram observadas em genótipos altamente resistentes, várias aglutinações da bactéria envolvidas por filamentos e estruturas rendilhadas sob pontuações da parede do vaso do xilema, não verificados em genótipos suscetíveis, o que sugere a ativação de mecanismos de defesa estruturais e bioquímicos nas plantas resistentes. 
A cultura do feijoeiro (Phaseolus vulgaris) está sujeita à incidência de vários patógenos que causam doenças e acarretam perdas significativas na produção. Progresso nos índices de produtividade tem sido alcançados com a utilização de medidas fitossanitárias, como seleção de sementes, uso de cultivares resistentes às doenças e rotação de culturas $(7,22)$. Dentre as doenças causadas em feijoeiro, pode ser citada a murcha-de-curtobacterium ou murcha bacteriana, causada por Curtobacterium flaccumfaciens pv. flaccumfaciens (Cff). A doença foi inicialmente descrita por Hedges em Dakota do Sul, nos EUA (3). A colonização de Cff em feijoeiro dá-se comumente em vasos de xilema (3). A semente de feijoeiro é o meio mais eficiente na disseminação de Cff, principalmente à longa distância (17). Os sintomas típicos da doença incluem murcha e amarelecimento das folhas e morte das plantas $(2,4)$.

Atualmente, o cultivo de feijão na região Centro-Sul do Brasil tem sido afetado pela murcha-de-curtobacterium, causando sérios danos e prejuízos à produção. Cff foi constatada pela primeira vez no Estado de São Paulo em 1995 (10). No Paraná, a partir de 2001, tem sido observada a ocorrência desta doença em diferentes regiões produtoras (5). Em Santa Catarina, sua presença foi confirmada no município de Campos Novos em 2001 (6) e, neste mesmo ano, ela foi observada pela primeira vez em feijoeiro da cultivar Pérola no município de Cristalina-GO (20). A primeira notificação da ocorrência de Cff em feijoeiro na região do Distrito Federal, deu-se em janeiro de 2002 (20).

$\mathrm{O}$ uso de genótipos resistentes ou tolerantes tem sido uma das medidas mais eficientes e econômicas para o controle de muitas doenças de plantas $(18,21)$ e é também o método mais prático e econômico para controle da murcha-de-curtobacterium na cultura do feijoeiro $(7,15)$. Neste sentido, o objetivo deste estudo foi determinar fontes de resistência genética, em uma amostra de 333 materiais pertencentes ao banco de germoplasma de feijoeiro do Instituto Agronômico (IAC) Campinas, SP, a Cff pela inoculação artificial em condições controladas. Foram também realizados estudos de microscopia eletrônica de varredura, visando comparar a colonização das células bacterianas em vasos do xilema em genótipos altamente resistentes e suscetíveis.

\section{MATERIAL E MÉTODOS}

Os experimentos de avaliação da resistência genética foram realizados em casa-de-vegetação, no Departamento de Produção Vegetal - Setor de Defesa Fitossanitária, FCA/UNESP, em Botucatu, SP. Foram avaliados 333 acessos de feijoeiros, pertencentes ao banco de germoplasma do Instituto Agronômico (IAC) - Campinas, SP, compostos por linhagens do ensaio de Valor de Cultivo e Uso - VCU, plantas provenientes de cruzamentos artificiais realizados entre fontes de genes de resistência a antracnose, mancha angular, crestamento bacteriano comum, variedades locais adaptadas e também plantas de grãos de outros tipos. Os genótipos foram avaliados por inoculação artificial com um isolado bacteriano (Cff Feij 2634). Neste estudo empregaram-se 5 repetições para cada genótipo e três plantas por vaso de $2 \mathrm{~L}$ contendo substrato autoclavado. Utilizou-se a cultivar Pérola como padrão de suscetibilidade.

Plântulas de feijoeiro, nove dias após a emergência, foram inoculadas na haste entre as folhas cotiledonares e primárias, por duas punções efetuada com agulha entomológica previamente umedecida em colônia bacteriana desenvolvida em meio NSA (8) por 96 horas a $28^{\circ} \mathrm{C}$. Plantas testemunhas foram inoculadas com água destilada.

Os sintomas da doença foram avaliados aos 30 dias após a inoculação, atribuindo-se notas que variaram de 0 a 9 , conforme Maringoni (8), onde: $0=$ sem sintomas da doença; $1=$ sintomas de clorose nas folhas; 3 = poucas folhas murchas $(1$ a 3 folhas, menos de $10 \%$ das folhas da planta); $5=$ aproximadamente $25 \%$ de folhas apresentam murchas e amarelecimento; $7=$ aproximadamente $50 \%$ de folhas murchas, amarelecimento e necrose de folíolos, plantas com nanismo; 9 = aproximadamente $75 \%$ ou mais de folhas com murcha e/ ou necrose, queda prematura de folhas, nanismo severo e/ou morte da planta. A escala de notas da severidade média da doença para cada genótipo foi denominada SMD.

A técnica da microscopia eletrônica de varredura foi utilizada para comparar a colonização das células bacterianas de Cff, no xilema de genótipos de feijoeiros anteriormente classificados como altamente resistentes e suscetíveis nos ensaios de avaliação de resistência. O delineamento experimental bem como a metodologia de inoculação empregadas foram os mesmos utilizados nos experimentos de avaliação de resistência. Trinta dias após as inoculações, procedeu-se um corte longitudinal no caule de cada genótipo de feijoeiro, previamente selecionado (Ac 297, Ac 405, Ac 592, Ac 546 e Ac 586) de aproximadamente $4 \mathrm{~cm}$ da região inoculada. As amostras de materiais vegetais foram fixadas em glutaraldeído $2,5 \%$ em tampão fosfato, 0,1 $\mathrm{M}, \mathrm{pH} 7,3$, seguidas de três lavagens em água destilada de dez minutos cada. A pós-fixação foi realizada em tetróxido de ósmio $0,5 \%$ em água destilada por 30 minutos, seguidas de desidratação em séries crescente de etanol $(7,5$ a $100 \%)$. Para a secagem das peças em aparelho de ponto crítico CPD-020 da Balzers, utilizou-se dióxido de carbono líquido. Em seguida as amostras foram montadas em "stubs", cobertas com $10 \mathrm{~nm}$ de ouro em Metalizador MED-010 da Balzers, e analisadas em microscópico eletrônico de varredura.

\section{RESULTADOS E DISCUSSÃO}

No conjunto de todos materiais avaliados, foram observados diferentes níveis de resistência. A partir da severidade média da doença (SMD), vinte e nove genótipos $(8,7 \%)$ foram classificados como altamente resistentes $(\mathrm{SMD}=0$ a 0,9$), 13$ genótipos $(3,9 \%)$ como resistentes $(\mathrm{SMD}=1,0$ a 2,9), 18 genótipos $(5,4 \%)$ como moderadamente resistentes (SMD $=3,0$ a 4,9) e os restantes 273 genótipos (82\%) como suscetíveis (SMD acima de 5,0) (Tabela 1).

Portanto, cerca de $18 \%$ dos materiais avaliados, desde altamente resistentes a moderadamente resistentes, podem ser úteis para o melhoramento como fonte de genes para resistência a Cff (19).

Sintomas de nanismo, murcha e amarelecimento de folhas seguidos de necrose foram desenvolvidos por genótipos suscetíveis enquanto nos genótipos resistentes se observaram plantas sem sintomas de murcha ou em média com um a dois pares de folhas murchas por planta. Por outro lado, plantas da cultivar Pérola sob as mesmas condições de ambiente evidenciaram sintomas de nanismo e amarelecimento, mas os sintomas observados na cultivar Pérola, foram menos severos que os apresentados pelos acessos Ac-546 e Ac-586, indicando para estes dois últimos genótipos maior suscetibilidade ao isolado bacteriano Cff Feij 2634 (Figura 1).

Estudos sobre avaliação da resistência genética para alguns genótipos de feijoeiro a Cff realizados por diferentes autores mostraram que um mesmo genótipo apresentou diferenças de comportamento a Cff. Assim, a cultivar IAPAR 14, considerada resistente a murcha-decurtobacterium por Leite Jr \& Behlau (5) apresentou reação de suscetibilidade no trabalho desenvolvido por Maringoni (9). O genótipo IAPAR 31, também considerado resistente por Leite Jr. \& Behlau (5) comportou-se como moderadamente resistente nos estudos realizados por Rava \& Costa (15), e suscetível aos dois isolados, testados por Maringoni (9). As cultivares IAC Carioca Pyatã e IAC Aruã foram 
Tabela 1. Reação de genótipos de feijoeiro à Curtobacterium flaccumfaciens pv. flaccumfaciens - Cff (isolado Cff Feij 2634)

\begin{tabular}{|c|c|c|c|c|c|c|c|c|}
\hline Acessos & Genótipos & $\mathbf{S M D}^{*}$ & Acessos & Genótipos & SMD $^{*}$ & Acessos & Genótipos & SMD* \\
\hline 5 & H96А98 & 0 & 622 & G. 2858 & 5,3 & 239 & México -435 & 7,9 \\
\hline 592 & Cal 153 & 0 & 652 & Raven & 5,3 & 415 & 73-VUL-3205 & 7,9 \\
\hline 597 & IAPAR 31 & 0 & 815 & RAZ-56 & 5,3 & 6 & H96Al 2 & 8,0 \\
\hline 01 & IAC Tybatã & 0 & 850 & Jabola (CB) & 5,3 & 6 & IAC UNA & 8,0 \\
\hline 1 & GEN 96A58 & 0 & 33 & IAC Carioca ETÉ & 5,4 & 2 & H96A13 & 8,0 \\
\hline 2 & H96A46 & 0,1 & 621 & A-449 & 5,4 & 8 & H96A82 & 8,1 \\
\hline \multirow[t]{2}{*}{22} & H96А 34 & 0,1 & 863 & Pirapora (CB) & 5,4 & 15 & Rosinha & \\
\hline & $\begin{array}{c}8,1 \\
\text { Verm. Desconhec. }\end{array}$ & 0,1 & 26 & H96А37 & 5,5 & 5 & GEN 96A31 & 8,2 \\
\hline 24 & H96A34 & 0,2 & 617 & Bat-332 & 5,5 & 10 & H96A28 & 8,2 \\
\hline 7 & H96А 58 & 0,2 & 749 & Car-Marron & 5,5 & 2 & Sanilac & 8,2 \\
\hline 297 & I-114 & 0,2 & 603 & R. bac & 5,6 & 21 & Baio de Praia & 8,2 \\
\hline 405 & TIB -3042 & 0,2 & 639 & Antioquia 8 & 5,6 & 31 & H96А98 & 8,3 \\
\hline 20 & H96A34 & 0,3 & 112 & Baetão & 5,7 & 11 & H96A3 & 8,3 \\
\hline 2 & H96A14 & 0,3 & 647 & Bat-477 & 5,7 & 12 & H96A54 & 8,3 \\
\hline 6 & H96A101 & 0,3 & 316 & Mamoninha & 5,8 & 17 & Rosinha & 8,3 \\
\hline 10 & H96A14 & 0,3 & 534 & Janapa & 5,8 & 6 & H96A5 & 8,4 \\
\hline 13 & H96A28 & 0,4 & 644 & Kaboon & 5,8 & 9 & H96А98 & 8,4 \\
\hline 2 & GEN 96A28 & 0,5 & 18 & IAC Carioca ETÉ & 5,8 & 23 & H96А 34 & 8,5 \\
\hline 16 & H96A 58 & 0,5 & 525 & Baetão & 5,9 & 34 & Pérola & 8,5 \\
\hline 7 & H96A55 & 0,5 & 649 & A-211 & 5,9 & 10 & H96A3 & 8,5 \\
\hline 12 & H96А98 & 0,6 & 837 & IAC Carioca ETÉ & 5,9 & 19 & H96A83 & 8,5 \\
\hline 12 & H96A55 & 0,6 & 8 & H96A28 & 6,0 & 02 & Rosinha & 8,5 \\
\hline 588 & Ovo de Codorna & 0,6 & 21 & H96А34 & 6,0 & 49 & Carioca 80 & 8,5 \\
\hline 16 & H96А 31 & 0,7 & 12 & H96A28 & 6,1 & 73 & Rosinha & 8,5 \\
\hline 7 & H96А98 & 0,8 & 32 & H96А98 & 6,5 & 109 & Red Kidney & 8,5 \\
\hline 19 & H96А34 & 0,8 & 18 & H96А98 & 6,7 & 348 & Preto do Procone & 8,5 \\
\hline 28 & H96A45 & 0,8 & 1 & H96А98 & 7,0 & 558 & Mulata Gorda & 8,5 \\
\hline 13 & H96A51 & 0,8 & 17 & H96A55 & 7,0 & 930 & Rosa Guaran. T. C & 8,5 \\
\hline 5 & H96A101 & 0,9 & 398 & Cormell-49242 & 7,0 & 1081 & CF-840743 & 8,5 \\
\hline 9 & H96А28 & 1,0 & 566 & Pijão & 7,0 & 4 & H96A51 & 8,6 \\
\hline 638 & $\mathrm{TO}$ & 1,1 & 663 & $\mathrm{~A}-322$ & 7,0 & 11 & H96A13 & 8,6 \\
\hline 658 & Fradinho & 1,2 & 672 & IAPAR 81 & 7,0 & 15 & H96A57 & 8,6 \\
\hline 1027 & Fradinho Cruzeiro & 1,2 & 13 & H96А98 & 7,1 & 3 & H96A51 & 8,6 \\
\hline 618 & $\mathrm{Mex}-54$ & 1,3 & 18 & H96A31 & 7,1 & 1 & Frijol Negro & 8,6 \\
\hline 6 & H96A56 & 1,3 & 213 & Preto-158 & 7,1 & 32 & Rosinha 127 & 8,6 \\
\hline 673 & MAN-38 & 1,5 & 395 & Mortino & 7,1 & 35 & ECU - 208 & 8,6 \\
\hline 14 & H96А3 & 1,5 & 595 & CNF-86-9 & 7,1 & 71 & Vermelhinho & 8,6 \\
\hline 677 & DOR-482 & 1,7 & 629 & Montcalm & 7,1 & 179 & Manteiguinha & 8,6 \\
\hline 5 & H96A50 & 1,8 & 14 & H96А98 & 7,2 & 251 & Costa Rica & 8,6 \\
\hline 15 & H96А 31 & 1,9 & 2 & $\mathrm{H} 96 \mathrm{~A} 102$ & 7,2 & 276 & $\mathrm{IPA}-8$ & 8,6 \\
\hline 7 & H96A18 & 2,0 & 13 & H96A56 & 7,2 & 320 & Black T. Soup. Bean & 8,6 \\
\hline 4 & H96A101 & 2,4 & 350 & Preto - 167 & 7,2 & 368 & Porrilo - 1 & 8,6 \\
\hline 4 & GEN $96 \mathrm{~A} 10$ & 3,0 & 604 & IAPAR 14 & 7,2 & 389 & Small Whit 59 Preto & 8,6 \\
\hline 818 & RAZ-59 & 3,0 & 699 & Bayo & 7,2 & 416 & Rosado - 13 & 8,6 \\
\hline 25 & Leg Floresta -5 & 3,1 & 3 & $\mathrm{H} 96 \mathrm{~A} 102$ & 7,3 & 457 & Cavalo Amarelo & 8,6 \\
\hline 641 & $\mathrm{ABC} 136$ & 3,1 & 11 & H96А28 & 7,3 & 478 & México - 12 & 8,6 \\
\hline 928 & WAF-74 & 3,1 & 9 & H96A5 & 7,3 & 528 & Baetão & 8,6 \\
\hline 1135 & Rosada & 3,1 & 16 & H96A55 & 7,3 & 546 & Gordo Branco & 8,6 \\
\hline 685 & G5207 & 3,2 & 596 & Iapar-Bac 6 & 7,3 & 569 & IAPAR - 72 & 8,6 \\
\hline 613 & D. Calima & 3,3 & 827 & Carioca Comum & 7,3 & 575 & RAI 76 & 8,6 \\
\hline 816 & RAZ-49 & 3,3 & 921 & Batista Brilhante CB & 7,3 & 616 & A-443 (Res.Bac) & 8,6 \\
\hline 25 & H96А 34 & 3,4 & 1 & H96A10 & 7,4 & 676 & DOR-476 & 8,6 \\
\hline 605 & LP 88-175 & 3,4 & 349 & Pato de Minas & 7,4 & 937 & Contender & 8,6 \\
\hline 680 & Durango-222 & 3,4 & 449 & Copinho G. Preto & 7,4 & 1062 & PR-733612 & 8,6 \\
\hline 684 & AND-279 & 3,4 & 612 & Bat. 93 & 7,4 & 17 & H96A31 & 8,6 \\
\hline 431 & BB LAKE & 3,8 & 911 & Goytacazes & 7,4 & 14 & H96А 56 & 8,6 \\
\hline 681 & Xan-112 & 3,9 & 339 & Rim de Porco & 7,5 & 20 & IAC UNA & 8,7 \\
\hline 926 & WAF-69 & 3,9 & 29 & H96А96 & 7,6 & 9 & H96A104 & 8,7 \\
\hline 8 & H96А37 & 4,0 & 319 & Preto - 196 & 7,6 & 11 & H96A55 & 8,7 \\
\hline 680 & Durango -222 & 4,2 & 427 & Safira & 7,6 & 28 & Uberabinha & 8,7 \\
\hline 624 & Mar. 01 & 5,0 & 819 & RAZ-55 & 7,6 & 74 & Enx (Diac. M. Pent) & 8,7 \\
\hline 3 & GEN 96A13 & 5,0 & 10 & H96A55 & 7,7 & 107 & Guatemala 2226 & 8,7 \\
\hline
\end{tabular}




\begin{tabular}{|c|c|c|c|c|c|c|c|c|}
\hline 385 & México - 488 & 8,7 & 160 & Uberabinha & 8,8 & 607 & Barbunya & 8,9 \\
\hline 392 & Perry Marron & 8,7 & 180 & Branco 119 & 8,8 & 608 & Pompador & 8,9 \\
\hline 439 & B-Puebla-40 & 8,7 & 186 & Coco Blanchi & 8,8 & 611 & Alemão & 8,9 \\
\hline 455 & Preto Lages & 8,7 & 215 & Pirata -1 & 8,8 & 614 & Pinto -114 & 8,9 \\
\hline 462 & Branco graúdo & 8,7 & 222 & Venezuela-42-5-1 & 8,8 & 619 & Flor de Mayo & 8,9 \\
\hline 481 & Carioca MG & 8,7 & 236 & Preto - 209 & 8,8 & 630 & HF 5465-63-1 & 8,9 \\
\hline 492 & G 11796 & 8,7 & 249 & Preto Uberabinha & 8,8 & 633 & RG-342 CH60 (MA) & 8,9 \\
\hline 521 & Chileno Preto & 8,7 & 254 & Quarenteno & 8,8 & 635 & Riz 30 & 8,9 \\
\hline 568 & IAPAR 57 & 8,7 & 278 & Venezuela -350 & 8,8 & 636 & G916 & 8,9 \\
\hline 573 & Jalo Itararé & 8,7 & 287 & Jamapa & 8,8 & 645 & G2333 & 8,9 \\
\hline 576 & EMB 81 & 8,7 & 288 & Rosinha & 8,8 & 648 & IPA - 1 & 8,9 \\
\hline 580 & Canejo & 8,7 & 311 & 73-VUL-320 & 8,8 & 674 & DOR -390 & 8,9 \\
\hline 586 & $\mathrm{ARC} 4$ & 8,7 & 354 & Preto -146 & 8,8 & 804 & Goiano Precoce & 8,9 \\
\hline 590 & Real Mexican 34 & 8,7 & 360 & MDRK & 8,8 & 905 & Rosa Guaranésio & 8,9 \\
\hline 600 & G 4000 & 8,7 & 373 & México-498 & 8,8 & 1052 & A-285 & 8,9 \\
\hline 615 & A-439 (Res.Bac.) & 8,7 & 374 & Monte Negro - 1349 & 8,8 & 1103 & PR-733639 & 8,9 \\
\hline 620 & Pan 72 & 8,7 & 393 & Feijão Ingá & 8,8 & 1121 & Feijão Pintado & 8,9 \\
\hline 632 & Aporé & 8,7 & 437 & A-ICA-TUI & 8,8 & 8 & H96A45 & 9,0 \\
\hline 643 & PI -207262 & 8,7 & 445 & B. Porrilo -70 & 8,8 & 30 & H96А96 & 9,0 \\
\hline 654 & A-21 & 8,7 & 465 & Corrilo Sintético & 8,8 & 17 & H96A9 & 9,0 \\
\hline 655 & A-55 & 8,7 & 499 & Feijão Verm. Graúdo & 8,8 & 1 & H96A13 & 9,0 \\
\hline 675 & DOR - 391 & 8,7 & 515 & Preto Dom Feliciano & 8,8 & 90 & B. Turrialba & 9,0 \\
\hline 679 & Turrialba -1 & 8,7 & 995 & Pompadair & 8,9 & 99 & México 115 & 9,0 \\
\hline 1114 & México 114 & 8,7 & 27 & H96А39 & 8,9 & 114 & Bataav & 9,0 \\
\hline 24 & Rosinha $145-1-1$ & 8,8 & & Rosinha & 8,9 & 154 & 60 Dias & 9,0 \\
\hline 72 & Alemão & 8,8 & 14 & H96A10 & 8,9 & 172 & IPA-2 & 9,0 \\
\hline 75 & Bagajo & 8,8 & 15 & H96A42 & 8,9 & 196 & HIBC & 9,0 \\
\hline 138 & Leg. Rosinha & 8,8 & 33 & Jalo & 8,9 & 203 & Rosado - 14 Mul. & 9,0 \\
\hline 171 & Vermelho de Minas & 8,8 & 50 & Chileno / Branco & 8,9 & 257 & Preto -184 & 9,0 \\
\hline 228 & México 44 & 8,8 & 550 & Caéte (Preta) & 8,9 & 267 & Honduras -32 & 9,0 \\
\hline 443 & Canário 101 & 8,8 & 556 & Rico - 23 & 8,9 & 268 & Rico & 9,0 \\
\hline 497 & Terra Velha & 8,8 & 567 & IAPAR 65 & 8,9 & 271 & Guatemala - 479 & 9,0 \\
\hline 543 & Jalo -110 & 8,8 & 570 & MD 806 & 8,9 & 531 & $\mathrm{PI}-310724$ & 9,0 \\
\hline 544 & IAPAR -80 & 8,8 & 571 & A 300 & 8,9 & 533 & Poebla -152 & 9,0 \\
\hline 610 & Oito e Nove & 8,8 & 572 & Jamapa & 8,9 & 583 & $\mathrm{ARC}-1$ & 9,0 \\
\hline 637 & TU & 8,8 & 574 & Puebla & 8,9 & 584 & $\mathrm{ARC}-2$ & 9,0 \\
\hline 646 & Méx - 279 & 8,8 & 577 & Jalo & 8,9 & 585 & $A R C-3$ & 9,0 \\
\hline 56 & $E C U-311$ & 8,8 & 578 & Tarumã & 8,9 & 602 & R. bac. & 9,0 \\
\hline 60 & Rim de Porco & 8,8 & 582 & IAPAR 44 & 8,9 & 606 & Apetito Branco & 9,0 \\
\hline 89 & Venezuela 350 & 8,8 & 589 & Sangre Toro & 8,9 & 618 & Méx - 54 & 9,0 \\
\hline 113 & Sem. Gde cor vinho & 8,8 & 593 & EMP -407 & 8,9 & 625 & Mar. 02 & 9,0 \\
\hline 149 & Baetão & 8,8 & 598 & EMP - 408 & 8,9 & 627 & Amendoim & 9,0 \\
\hline 152 & STO-ROSS & 8,8 & 599 & $\mathrm{AFR}-188$ & 8,9 & 628 & Cal 143 & 9,0 \\
\hline
\end{tabular}

*SMD - Escala de notas da severidade média da doença de 0 a 9,0 (Maringoni, 2000)

consideradas moderadamente resistentes por Rava \& Costa (16), mas foram as mais resistentes dentre as testadas por Maringoni (8).

No presente trabalho, IAC Tybatã e IAPAR 31 se comportaram como resistentes, em conformidade com os dados de Leite Jr. \& Behlau (5), enquanto IAPAR 14 apresentou reação de suscetibilidade, confirmando o resultado obtido por Maringoni (9).

Vale a pena ressaltar que os dados apresentados foram obtidos de experimentos desenvolvidos em diferentes localidades, portanto sob diferentes condições climáticas, utilizando diferentes isolados bacterianos.

Esta tendência dos genótipos apresentarem comportamento diferente dependendo do isolado bacteriano utilizado pode ser devido à variabilidade de agressividade em isolados de Cff e demonstra a importância em se trabalhar com uma mistura de isolados da bactéria em experimento de avaliação de resistência.

Utilizando-se da técnica de microscopia eletrônica de varredura, foi possível visualizar em vasos de xilema de feijoeiro altamente resistente, Ac-297, Ac-405 e Ac-592, (Figuras 2A, 2B e 2C), várias células bacterianas de Cff aglutinadas. Anteriormente à formação desses aglomerados bacterianos, verificou-se inicialmente a formação de uma rede filamentosa sob a superfície das células bacterianas. Esses filamentos, inicialmente, formavam ligações entre células próximas e distantes na região do xilema, diminuindo as distâncias entre as bactérias formando subseqüentemente as aglutinações, que provavelmente, impossibilitavam o deslocamento de Cff para outras regiões do vaso do xilema a partir do ponto de inoculação, em genótipos de feijoeiro altamente resistentes. Concomitantemente a essas aglutinações, foi também observado crescimento de estrutura rendilhada sob as pontuações das paredes do xilema (Figura 2D) que, aparentemente, impossibilitou o avanço e proliferação da bactéria para regiões adjacentes, limitando o crescimento da população bacteriana. Tais observações sugerem a atuação de mecanismo de resistência física e bioquímica pós-formados em genótipos de feijoeiro altamente resistentes. Nos genótipos de feijoeiros suscetíveis Ac-546 e Ac-586 (Figuras 2E e 2F), foi verificado grande número de células bacterianas sob as pontuações da parede do vaso do xilema; no entanto, o acesso Ac-546 apresentou pequenas formações de estrutura rendilhada. Esta observação sugere a hipótese de que embora possa ter ocorrido uma 


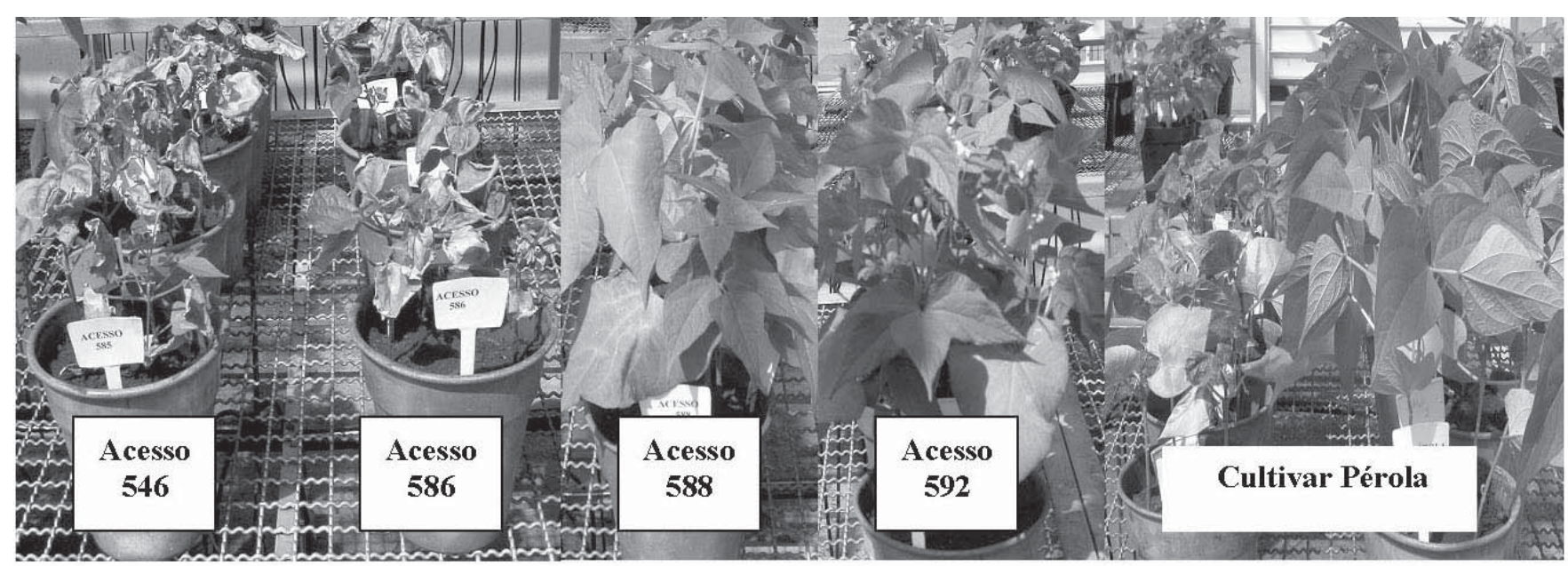

Figura 1. Sintomas de murcha-de-curtobacterium em feijoeiros inoculados com o isolado Cff Feij 2634,

30 dias após a inoculação.

Acessos 546 e 586 - genótipos suscetíveis.

Acessos 588 e 592 - genótipos altamente resistentes.

Cultivar Pérola - fileira à direita: controle inoculado apenas com água destilada.
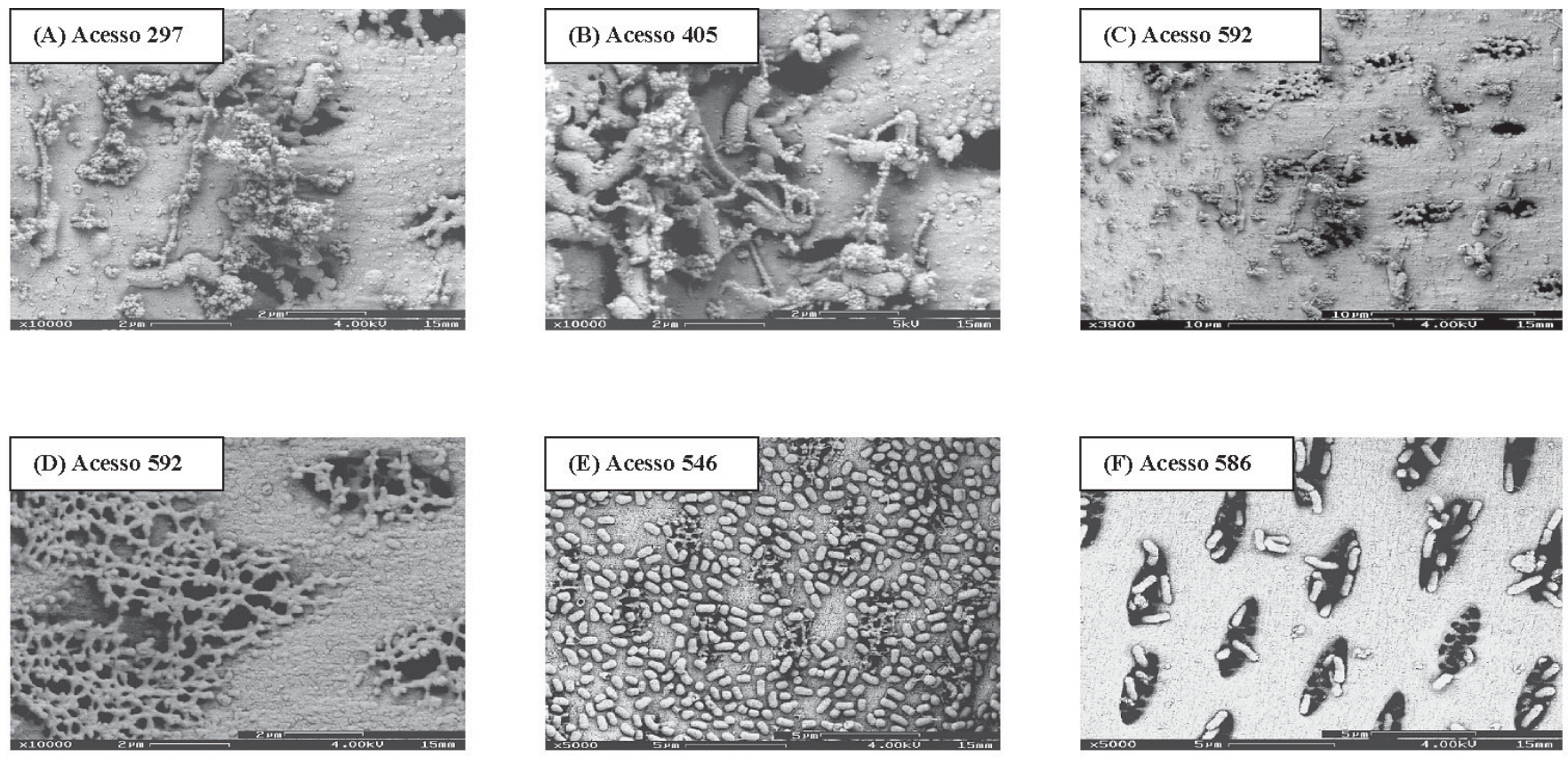

Figura 2. Micrografias eletrônicas de varredura de Curtobacterium flaccumfaciens pv. flaccumfaciens em vasos de xilema de feijoeiro.

A, B e C-genótipos altamente resistentes

$\mathrm{D}$ - estrutura rendilhada em genótipo altamente resistente

E e F - Células bacterianas nas pontuações da parede de xilema em genótipos suscetíveis

ativação do mecanismo de resistência no genótipo Ac-546, esta ativação deve ter ocorrido tardiamente em menor intensidade que a dinâmica do crescimento populacional de Cff.

A presença de pontuações guarnecidas é comum em vasos do xilema de espécies de Caesalpinaceae e Fabaceae (13). Tais guarnições são descritas como projeções da parede celular rendilhada encontrada em muitas leguminosas, sendo especialmente características de plantas de clima temperado, nas quais tais formações têm sido associadas a mecanismos de resistência a baixas temperaturas que podem provocar o congelamento da seiva do xilema. Assim, é de grande interesse esclarecer se as estruturas rendilhadas observadas nos feijoeiros resistentes a Cff estão relacionadas às guarnições das pontuações comumente encontradas em leguminosas e, neste caso induzidas como resposta de resistência estrutural à presença do patógeno nos vasos do xilema. Dentre as barreiras morfológicas induzidas pelas plantas em conseqüência da invasão sistêmica pelo patógeno, a mais freqüente é a formação de tiloses nos vasos do xilema. Projeções protoplasmáticas no interior dos vasos do xilema resultam na sua obstrução e restrição 
no avanço do patógeno (11). De maneira geral, plantas resistentes às murchas vasculares exibem a capacidade de formar maiores quantidades de tiloses do que plantas suscetíveis (11). Rahman et al. (14), em estudos de microscopia eletrônica de transmissão, analisaram a colonização vascular de cultivares resistentes e suscetíveis de pimentão (Capsicum annuum) por Ralstonia solanacearum e observaram que nas plantas resistentes, vasos do xilema adjacentes à região de infecção foram recobertos pela expansão da parede celular, limitando a dispersão e levando à conseqüente redução do inóculo.

Para Xanthomonas axonopodis pv. Phaseoli, Contreras et al. (1) analisaram as mudanças ocorridas a nível celular, na epiderme, mesófilo e tecido vascular de folhas de feijoeiro em genótipos resistentes, moderadamente resistentes e suscetíveis. Em genótipos resistentes, os autores verificaram encapsulamento das células bacterianas. Nos moderadamente resistentes, observaram poucas bactérias nos espaços intercelulares e a formação de vesículas entre o plasmalema e a parede celular, enquanto que nos genótipos suscetíveis, notaram maior número de bactérias nos espaços intercelulares, condensação do citoplasma desintegração de organelas, rompimento da lamela média e penetração no tecido vascular (vasos do metaxilema) de massas de células bacterianas.

Além de fatores de ordem morfológica e funcional já descritos no presente trabalho, a resistência de plantas a doenças está associada a uma série de outras respostas desenvolvidas pelo hospedeiro após contato com agentes patogênicos. A resistência é freqüentemente manifestada como uma reação de hipersensibilidade, que resulta na morte celular localizada no sítio de penetração do patógeno. Outras respostas de resistência da planta a patógenos estão relacionadas à produção de fitoalexinas, que são compostos antimicrobianos de baixo peso molecular, sintetizados e acumulados nas plantas após o contato com microrganismos (12).

Estudos futuros de investigação dos mecanismos de ação que podem estar relacionados a fatores estruturais e bioquímicos pré ou pós-formados devem ser realizados como forma de entendimento da resistência e suscetibilidade de genótipos à $C$. flaccumfaciens pv. flaccumfaciens.

\section{REFERÊNCIAS BIBLIOGRÁFICAS}

1. Contreras, N.; Trujilo, G.; Borges, O.; Centeno, F. Análisis ultraestructural de la interacción de Xanthomonas axonopodis pv. phaseoli con genotipos resistentes, moderadamente resistentes y susceptibles de Phaseolus vulgaris L. Interciencia, Caracas, v.26, n. 11, p. 554-557, 2001.

2. Hall, R. Compendium of Bean Diseases. St. Paul: APS Press, p.31, 1991

3. Hedges, F. A bacterial wilt of the bean caused by Bacterium flaccumfaciens nov. sp. Science, Washington, v.55, n.1425, p.433-434, 1922.

4. Hedges, F. Bacterial wilt of beans (Bacterium flaccumfaciens Hedges), including comparisons with Bacterium phaseoli. Phytopathology, St. Paul, v.16, n.1, p.1-22, 1926.

5. Leite Jr., R.P.; Behlau, F. Reação de genótipos de feijoeiro à murcha bacteriana causada por Curtobacterium flaccumfaciens pv.flaccumfaciens. Fitopatologia Brasileira, Fortaleza, v.27, supl., p.62, 2002 (Resumo).

6. Leite Jr., R.P.; Meneguim, L.; Behlau, F.; Rodrigues, S.R.; Biachini, A. Ocorrência de Curtobacterium flaccumfaciens pv. flaccumfaciens em feijoeiro no Paraná e Santa Catarina. Fitopatologia Brasi- leira, Brasília, v.26, supl., p.303-304, 2001 (Resumo).

7. Maringoni, A.C. Detecção de Xanthomonas campestris pv. phaseoli (Smith) Dye em sementes de feijoeiro e consequências epidemiológicas. 1993. 132f. Tese (Doutorado em Agronomia/ Fitopatologia) - Escola Superior de Agricultura "Luiz de Queiroz”, Universidade de São Paulo, Piracicaba.

8. Maringoni, A.C. Caracterização de isolados de Curtobacterium flaccumfaciens pv. flaccumfaciens e avaliação da resistência de cultivares de feijoeiro comum à murcha-de-curtobacterium. 2000. 73f. Tese (Livre-Docência) - Faculdade de Ciências Agronômicas, Universidade Estadual Paulista, Botucatu.

9. Maringoni, A.C. Comportamento de cultivares de feijoeiro comum à murcha-de-curtobacterium. Fitopatologia Brasileira, Fortaleza, v. 27, n.2, p.157-162, 2002.

10. Maringoni, A.C.; Rosa, E.F. Ocorrência de Curtobacterium flaccumfaciens pv. flaccumfaciens em feijoeiro no Estado de São Paulo. Summa Phytopathologica, Botucatu, v.23, n.2, p.160-162, 1997.

11. Pascholati, S.F.; Leite, B. Hospedeiro: mecanismos de resistência. In: Bergamin Filho, A.; Kimati, H.; Amorim, L. (Ed.). Manual de Fitopatologia. $3^{\text {-a }}$ ed. São Paulo: Agronômica Ceres, 1995. v.1, p.417453.

12. Paxton, J.D. Phytoalexins: a working redefinition. Phytopathologische Zeitschrift, Berlin, v.101, n.12, p.106-109, 1981.

13. Quirk, J.T.; Miller, R.B. Vestured pits in the tribe Cassieae Bronn (Leguminosae). IAWA Bulletin, Leiden, v.3, n.6, p. 200-212, 1985.

14. Rahman, M.A.; Abdullah, H.; Vanhaecke, M. Histopathology of susceptible and resistant Capsicum annuum cultivars infected with Ralstonia solanacearum. Journal of Phytopathology, Berlin, v.147, n.4, p.129-140, 1999.

15. Rava, C.A.; Costa, J.G.C. Reação de cultivares de feijoeiro comum à Murcha-de-curtobacterium. In: Reunião Sul-Brasileira de Feijão, 5.; Reunião Anual Paranense, 2001, Londrina. Anais. Londrina: Instituto Agronômico do Paraná, 2001. p.55-56.

16. Rava, C.A.; Costa, J.G.C.; Fonseca, J.R.; Salgado, A.L. Procura de fontes de resistência à murcha-de-curtobacterium em coletas de feijoeiro-comum. In: Congresso Nacional de Pesquisa de Feijão, 7., 2002, Viçosa. Resumos Expandidos. Viçosa: UFV, 2002. p.128-129.

17. Saettler, A.W.; Perry, S.K. Seed-transmitted bacterial diseases in Michigan navy (pea) beans, Phaseolus vulgaris. Plant Disease Reporter, St. Paul, v.56, n.5, p.378-381, 1972.

18. Sinclair, J.B. Compedium of Soybean Diseases. 2 nd. ed. St. Paul: The American Phytopathological Society, 1982. 104p.

19. Souza, V.L.; Maringoni, A.C.; Carbonell, S.A.M.; Ito, M.F. Detecção de resistência à murcha-de-Curtobacterium em genótipos de feijoeiro. Summa Phytopathologica, Botucatu, v.30, n.1, p.90, 2004 (Resumo).

20. Uesugi, C.H.; Freitas, M.A.; Menezes, J.R.; Abadio, A.K.R.; Pinho, D.S.; Araújo, G.J. P. Ocorrência de Curtobacterium flaccumfaciens pv.flaccumfaciens em feijoeiro na região geoeconômica do Distrito Federal. Fitopatologia Brasileira, Fortaleza, v.27, supl., p.71-72, 2002 (Resumo).

21. Vanderplank, J.E. Disease Resistance in Plants. New York: Academic Press, 1968. 206p.

22. Vieira, J.L.T.M. Produção e comercialização no Brasil. In: Zimmermann, M.J.O.; Rocha, M.; Yamada, T. (Ed.). Cultura do feijoeiro: fatores que afetam a produtividade. Piracicaba: Associação para a Pesquisa da Potassa e do Fosfato, 1988. p.21-35. 